\title{
Extending Humanitarian Assistance to the Survivors of Gender-Based Violence in Ukraine
}

\section{Saurabh RamBihariLal Shrivastava*, Prateek Saurabh Shrivastava and Jegadeesh Ramasamy}

Department of Community Medicine, Shri Sathya Sai Medical College and Research Institute, India

\section{Introduction}

Globally, violence against women is quite a common phenomenon, not only by the intimate partner, but even by other males [1]. It is a shocking estimate that 1 in 3 women have been exposed to an act of violence and violation of their basic human rights, at least once in their lifetime worldwide [1]. This is alarming as stakeholders from different nations and international welfare agencies have expressed their concern in this regard for many decades and have even incorporated accomplishment of gender equality in the society for the empowerment of the women [1].

Furthermore, the scenario becomes even more complicated in areas which are experiencing some form of humanitarian emergency or population displacement due to the lack of vocational opportunities, stress, loss of property, insecurity, and even a belief among the perpetrators that no action can be taken against them due to the lacunae in the enforcement of the law and order in the region [2-4]. In-fact, a sharp rise in the incidence of violence against women has been reported in a number of nations experiencing conflict in Africa and Middle-East region, and that the health sector has failed badly in responding to the needs of the vulnerable women $[2,3]$.

Even in the eastern part of Ukraine, which is experiencing conflicts for more than two years now, a massive toll on people has been reported [5]. The available estimate suggests that in excess of 3 million people are in need of emergency humanitarian assistance, and almost 1.7 million people have been internally displaced, which includes susceptible population groups of women, children and people with disabilities [5]. Moreover, women in the region have been exposed to abduction, trafficking, physical abuse, killings, sexual slavery, harassment, forced marriage, early childbearing related complications, mental trauma, and human rights violation on a daily basis [1,3-5].
In an attempt to provide psychosocial support to the people affected by the ongoing conflict in the region, the United Nations Population Fund has deployed more than 25 mobile teams [5]. These mobile teams comprise of a social worker, a psychologist and an outreach worker, all of them are being trained in assisting survivors of gender-based violence [5]. However, owing to their mobile nature, these teams aim to reach remote areas and work with an intention to connect people with welfare services, after establishing a feeling of trust with the survivors [5]. In addition, a case-based customized help is offered to the survivors after determining their needs, be it psychosocial support or addressing the emotional needs of children or even shelter [5]. Moreover, since the start of these relief or welfare activities, more than ten thousand survivors of gender-based violence have been identified and supported with desired care, so that they can start their life afresh [5].

To conclude, violence against women during conflicts has shown an alarming upward trend. It is high time that welfare agencies should expand the reach of their services to ensure that all vulnerable women are provided with timely assistance and at the same time men counterparts are also counseled to refrain from such activities against women.

\section{References}

1. World Health Organization (2016) Violence against women: Intimate partne and sexual violence against women - Fact sheet No. 239.

2. Shrivastava SR, Shrivastava PS, Ramasamy J (2016) Implementing universal minimal standards to counter the challenge of gender-based violence in emergencies. Ann Trop Med Public Health 9: 289-290.

3. Freedman J (2016) Sexual and gender-based violence against refugee women: A hidden aspect of the refugee "crisis". Reprod Health Matters 24: 18-26.

4. Heidari S, Moreno CG (2016) Gender-based violence: a barrier to sexual and reproductive health and rights. Reprod Health Matters 24: 1-4.

5. UNFPA (2016) After long nightmare in Ukraine, displaced family finds peace.

Received December 15, 2016; Accepted December 19, 2016; Published December 26, 2016

Citation: Shrivastava SR, Shrivastava PS, Ramasamy J (2016) Extending Humanitarian Assistance to the Survivors of Gender-Based Violence in Ukraine. Primary Health Care 6: e117. doi:10.4172/2167-1079.1000e117

Copyright: $\odot 2016$ Shrivastava SR, et al. This is an open-access article distributed under the terms of the Creative Commons Attribution License, which permits unrestricted use, distribution, and reproduction in any medium, provided the original author and source are credited. 